\title{
Disaster Risk Reduction Efforts in the Greater Horn of Africa
}

\author{
Marie-Ange Baudoin • Tsegay Wolde-Georgis
}

Published online: 25 February 2015

(c) The Author(s) 2015. This article is published with open access at Springerlink.com

\begin{abstract}
This article assesses the current state of disaster risk reduction (DRR) in the Greater Horn of Africa (GHA), and focuses on interventions and policies to mitigate hydrometeorological risks. The research analyzes, as main case study, the program "Regional Climate Prediction and Risk Reduction in the Greater Horn of Africa" funded by the Office of U.S. Foreign Disaster Assistance (USAID OFDA) in the early 2000 that targeted risk preparedness. The research method combines a desk review of relevant documents and research papers with surveys and interviews directed to key proponents of DRR across the GHA. Results highlight current strengths and weaknesses in the way DRR is implemented in the GHA. Significant improvements in the climate-forecasting capabilities in the GHA since the 2000s are acknowledged, but the practice of DRR remains technology driven and impacts on the ground are limited. The key findings highlight the significant communication gaps that exist between the producers of climate information and their end users, the communities at risk. The article urges the establishment of bridges that connect climate experts, policymakers, and representatives of the local communities, and for the implementation of a feedback loop from forecast users to their producers, in order to strengthen risk resilience across the GHA.
\end{abstract}

Keywords Climate change $\cdot$ Disaster risk management - Greater Horn of Africa $\cdot$ Hydrometeorological hazards · Lessons learned $\cdot$ Sub-Saharan Africa

M.-A. Baudoin $(\bowtie) \cdot$ T. Wolde-Georgis

Consortium for Capacity Building, Institute of Arctic and Alpine

Research (INSTAAR), University of Colorado, Boulder, CO 80309-0450, USA

e-mail: marieange007@gmail.com

\section{Introduction}

Sub-Saharan Africa (SSA) in general, and the greater Horn of Africa in particular, is one of the most disaster-prone regions of the world (IPCC 2007, 2012). Despite significant improvements in the prediction of hydrometeorological (HM) hazard (Hellmuth et al. 2007; Bailey 2013), many challenges remain to effectively mitigate impacts on society. As such, in 2013, Bailey pointed out: "Famine early warning systems have a good track record of predicting food crises but a poor track record of triggering early action" (Bailey 2013, p. 9).

This quote can be applied to the 2010 droughts that affected the Greater Horn of Africa (GHA). Despite the clear warnings of food shortage risks disseminated to African governments and to the international community months in advance, most interventions and support for impacted populations took place after the consequences of the droughts were felt. The response delay resulted in the displacement of millions, increased malnutrition, and sometimes death (UNISDR 2012). This kind of disaster risks is expected to increase in the future due to climate change, whose impacts are likely to heighten the severity and occurrence of extreme HM events, such as droughts and floods (Stern 2007, p. 76; IPCC 2007, 2012). Consequences in GHA in particular will include negative shocks on food security, on the recent progress made in economic development, and on overall poverty reduction efforts (World Bank 2012, 2013).

In the context of a changing climate, development aid agencies are seeking to improve their interventions in the field of disaster risk reduction (DRR) in Africa. Improvements are all the more important because of costly recurring disaster recovery measures in the same locations (for example, in Kenya) in the context of a stagnation of international fund for development aid (Ferris and Petz 2012). To address these 
challenges, organizations involved in DRR will have to be more efficient and cost-effective. Since the early 2000s, major bilateral and multilateral agencies have endorsed a shift from investing most resources in disaster response, relief, and recovery to enhancing risk predictions, preparedness, and mitigation (UNISDR 2012; USAID 2012). This shift has also been promoted, earlier, in the development and risk literature (Holloway 2003; Vermaak and van Niekerk 2004). Similarly, recognizing the high vulnerability of their continent to climate-related hazards and climate change, African leaders have also invested resources in forecasting technologies (Ogallo et al. 2008).

Based on interviews and a desk review of project documents and scientific research, this article assesses the current strengths and weaknesses in implementing DRR strategies in the GHA. This region comprises the African Horn and the Great Lake region. The study is conducted in light of the support provided through a major DRR program called "Regional Climate Prediction and Risk Reduction in the Greater Horn of Africa" applied in the region between 2001 and 2005, funded by the Office of U.S. Foreign Disaster Assistance (USAID OFDA), and implemented with support of international institutions with relevant expertise in the field of hydrometeorological risk prediction. Recent enhancements of risk preparedness, endorsed by African states after this program was completed, are also considered in the study.

The GHA has been affected by many hydrometeorological hazards in the past; thus, many scholars have studied success and failure in managing such events in order to highlight "lessons learned" for future DRR interventions (Glantz et al. 1997; Glantz 2000; Hellmuth et al. 2007). In this article, we evaluate whether an increased focus on risk predictions and preparedness, confirmed in the literature and in strategic documents from agencies working in the field of DRR, has effectively contributed to reduce impacts of hydrometeorological risks on society in the GHA. The results acknowledge strengths and weaknesses about DRR activities, as well as opportunities to foster this practice in the GHA. These findings are also documented and supported by other studies (Glantz 2000; Hellmuth et al. 2007; World Bank 2010; UNISDR 2012), which suggest that a lesson is not learned until it is applied. The article concludes with a set of lessons relevant for aid agencies and for African governments seeking to mitigate future impacts of hydrometeorological hazards on society, and to strengthen livelihood resilience to a changing climate.

\section{Context, Material, and Methods}

This section aims to underline the impacts of hydrometeorological hazard in Sub-Saharan Africa and, more precisely, in the GHA. As the context and disaster-related issues are described, the needs for acute and effective DRR interventions are identified. Then, the research approach and methods for data collection, as well as the size of the data set used in this study, are explained.

\subsection{Context and Problems}

The number of natural disasters in SSA has increased over the last four decades, resulting in a growing number of victims, especially located in the African Horn (Fig. 1) (Nicholson 2014). In this region people are extremely vulnerable to severe drought events, which are more frequent and more destructive than any other types of hazard (Fig. 1). For instance, there have been associations between the chronologies of El Nino episode and drought in Ethiopia (Wolde-Georgis 1997). In addition to a high exposition to extreme events, impacts in SSA are heightened by weak disaster risk management capacities, and a high vulnerability among the population (Hellmuth et al. 2007). Risk vulnerability is linked to inadequate human, economic, and infrastructure development, coupled with high population growth, increasing urbanization, and dangerous locations for settlement (UNECA 2011). Hydrometeorological hazards particularly affect livelihood conditions and economic development in rural areas, as they rely on rain fed agriculture. This economic and subsistence activity is extremely sensitive to unreliable and variable rainfall patterns characterizing this region (Hansen et al. 2011). In this specific context, hazards such as droughts and floods often turn into disasters, mainly affecting poor vulnerable communities, and significantly slowing down development and economic gains (World Bank 2012). This study focuses on the GHA (Fig. 2), located in the northeastern quadrant of SSA. The region comprises the following countries: Burundi, Djibouti, Eritrea, Ethiopia, Kenya, Rwanda, Somalia, Sudan, South Sudan, Tanzania, and Uganda.

To mitigate natural hazard impacts in this region, international aid agencies have developed and implemented DRR programs for decades. Since the early 2000s, programs that specifically targeted HM hazards have contributed to improvement in the prediction of such events over the subcontinent (Hellmuth et al. 2007; Glantz and Baudoin 2014). But significant problems remain, since in 2011 Clark (from the United Nations Development Programme) declared: "In 2011 alone [in the world], almost 30,000 people were killed in 302 disasters, and 206 million people were affected, including 106 million by floods, and 60 million by drought-mainly in the Horn of Africa" (Clark 2012).

Without improvements in the practice of DRR, the GHA will be increasingly affected by the impacts of HM events. According to the Intergovernmental Panel on Climate 


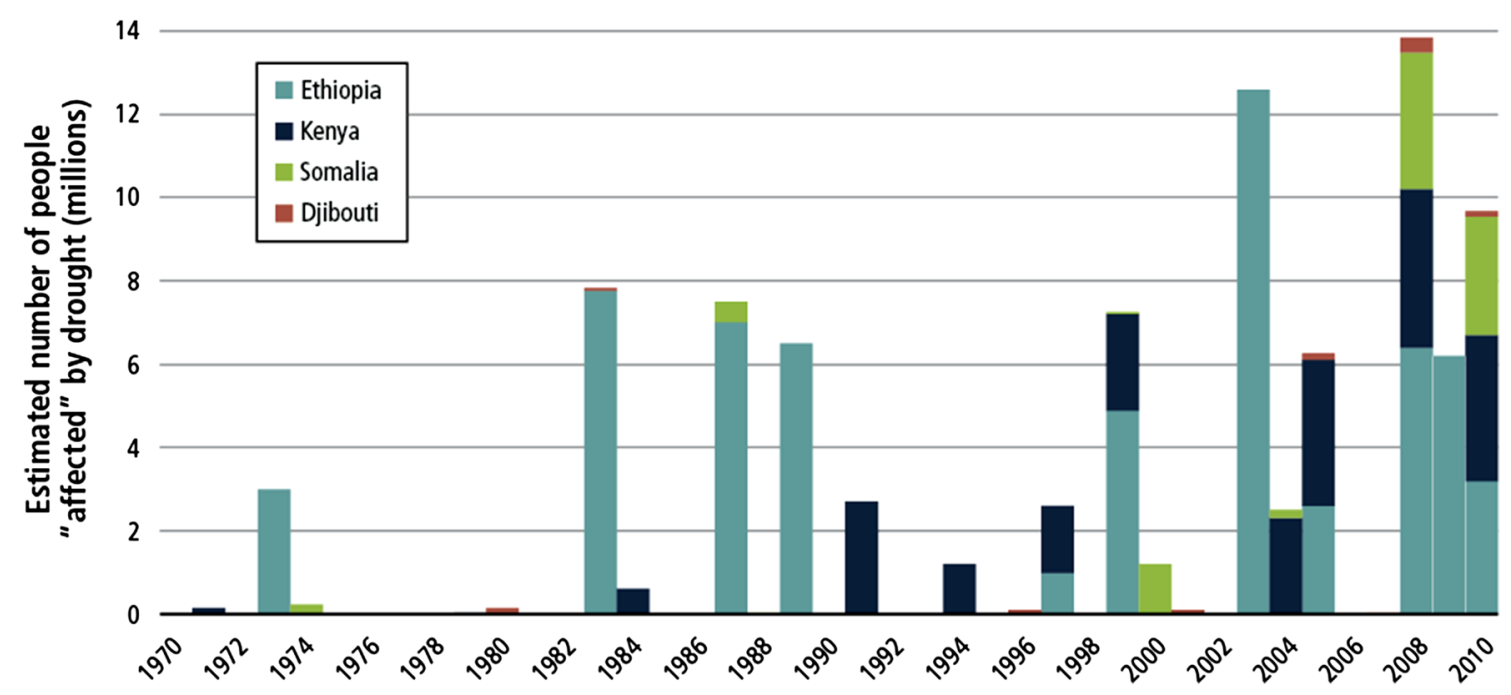

Fig. 1 Number of people affected by droughts in the African Horn, between 1970 and 2010. Source IFPRI (n.d.)

Fig. 2 The Greater Horn of Africa

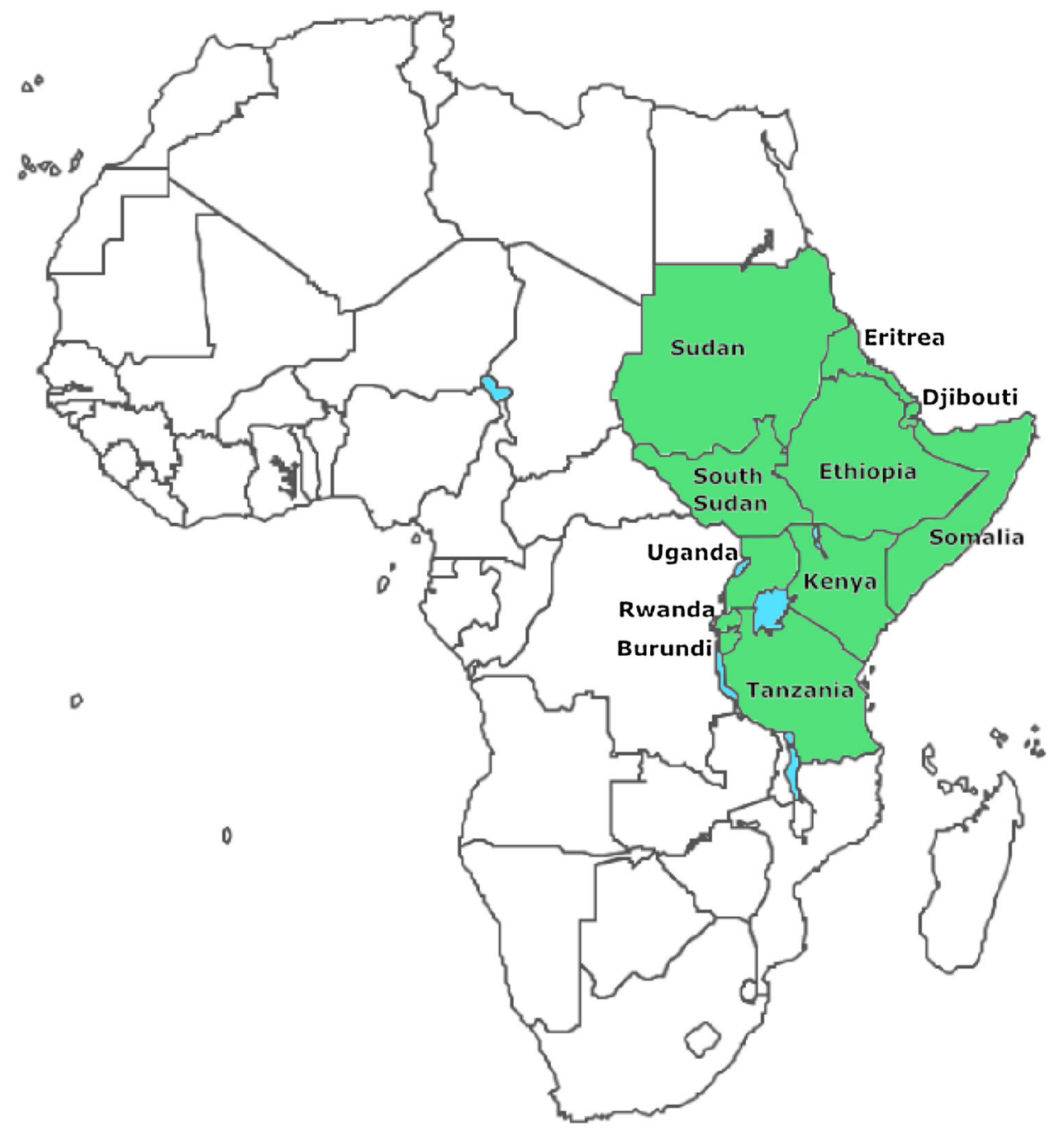


Change (IPCC), climate change in SSA will likely result in increased hydrological stresses (expected as early as 2020); intensified extreme events (storms, dry spells, and so on); modified precipitation patterns; and heightened rainfall variability (IPCC 2007). The location and intensity of these anticipated climate change impacts remain difficult to predict, especially at the local level (UNECA 2011). In order to better forecast HM risks, and prepare for their impacts, the Intergovernmental Authority on Development's Climate Prediction and Applications Center (ICPAC-http://www.icpac.net/) was established in Nairobi in 1989 (formerly named Drought Monitoring Center (DMC) for the Greater Horn of Africa). This climate science center plays a key role in the GHA, training hydrometeorologists from across the region, and working to improve the accuracy of seasonal forecasts.

\subsection{Strengths and Weaknesses in the Practice of DRR}

An important set of lessons to improve the practice of DRR in sub-Saharan Africa can be found through a review of relevant literature (Glantz 2000; Hellmuth et al. 2007; Glantz and Baudoin 2014). A recurrent observation in this region, documented through interviews conducted for this study, is the existing limits in forecasting capacities, which are due to incomplete or unavailable historical, long-term climatic data as well as a lack of up-to-date technologies and experienced staff among climate institutions (Hellmuth et al. 2007; Baudoin et al. 2014). In fact, most of the climate information that is monitored to predict HM risks in SSA is actually processed in international and foreign centers (Baudoin 2012; Glantz and Baudoin 2014).

Hellmuth et al. (2007) and Holloway et al. (2010) also underline difficulties in disseminating risk information to the vulnerable communities in SSA. This is especially true in remote areas where communication facilities are often missing, but not only. Communication with local African communities is often hampered by the complex terminology used to release forecasts and risk warnings, the lack of communication infrastructure, and, perhaps, a lack of understanding of modern scientific meteorology among farmers (Shah et al. 2012). Trust issues between climate scientists and local communities, which are the end users of the forecasts, can also affect the effectiveness of risk alerts, as pointed out by Archer (2003), Hansen et al. (2011), and Baudoin et al. (2014).

Poverty is another barrier. Even if perfect information is transmitted to farmers, their responses are often constrained by a lack of adequate resources (material or financial). Moreover, the absence of social security nets, such as savings and risk insurance, in many African rural communities, limit farmers' readiness to try new practices in responses to climate-related risks (Lallau 2008). Buchanan-Smith et al. (1994) emphasized that the prevention of famine in SSA has not improved since the disasters of the 1980s, despite better predictive capacity in the Sahel and the Horn of Africa. Regardless of accuracy, information cannot be eaten by famine-inflicted communities. Regrettably, a similar assessment appeared in Bailey's (2013) report on famine in Africa, published 20 years later.

Another limit to effective risk management in SSA is a lack of preparedness planning and disaster response strategies among most governments (UNISDR 2012); such plans are necessary to apply timely responses to imminent disaster threats. In reality, governments tend to rely on support from the international community to face, or recover from, natural hazards. Support from the international community is often delayed by administrative processes within aid agencies, or by disaster diplomacy in international relations. Consequently, international help often takes place after a disaster has occurred, in the form of relief and recovery support (Holloway 2003; Vermaak and van Niekerk 2004; Holloway and Roomaney 2008; Holloway et al. 2010). Such relief provision, although necessary, does not contribute to efforts that build a country's capacities to manage future disaster risks. In fact, one might say that they create a certain dependency of the recipient countries towards international aid in time of disaster.

Recognizing these multiple limits to DRR, major aid agencies have endorsed a shift from focusing on disaster relief to enhancing risk preparedness and prevention. This shift also aims to reduce costly spending in recovery support and to prepare better for the expected rise of $\mathrm{HM}$ hazards in the context of climate change (USAID 2012). Increased attention given to risk preparedness in DRR programs has emerged in the early 2000s, with a strong emphasis on enhancing climate forecasting capacity.

\subsection{Methodology, Scope, and Limits}

An evaluation of DRR in the GHA was conducted in light of the support provided by OFDA's DRR program: "Regional Climate Prediction and Risk Reduction in the Greater Horn of Africa" implemented across the region at the end of 2001. This program, and its site of implementation, constitute our case study for this research. The research method combines a desk review of relevant documents, including scientific articles on DRR, official documents about hazard management in SSA, and reports from development aid agencies working in the field of DRR in the region. Results were complemented with 
qualitative data collected through surveys and interviews conducted during a short field trip in Nairobi, Kenya, in February 2013.

Nairobi was selected as an investigation site because it hosts the ICPAC and most of the project investigators (PIs) involved in the program "Regional Climate Prediction and Risk Reduction in the Greater Horn of Africa" are still located there, especially within ICPAC. Therefore, this site was deemed as a fertile area in which to gather data about the implementation of this DRR program and its long-term impacts and to evaluate the current role and activities led by ICPAC in the GHA. Due to time and resource constraints, we were not able to conduct relevant field investigations in other member countries of the GHA. Moreover, due to the short duration of our stay in Kenya, the investigation focused on Nairobi and its surroundings. It should, however, be noted that Nairobi does not necessarily represent the whole region in terms of capacities to forecast hazards' risks and to implement DRR activities, due to its particularities of hosting ICPAC, an important regional climate center and a key actor in the implementation of the "Regional Climate Prediction and Risk Reduction in the Greater Horn of Africa" program.

The data base of this study is comprised of eight written surveys from the National Hydrometeorological Services (NHMSs) located in the GHA; and 13 semi-oriented individual interviews conducted in Nairobi, Kenya, with: four PIs involved in the "Regional Climate Prediction and Risk Reduction in the Greater Horn of Africa" program, including two members of ICPAC, one member of the International Research Institute for Climate and Society (IRI), and a professor at the University of Nairobi; one member of the Kenyan Meteorological Department (KMD); a project manager working in the NGO One Acre Fund; a representative of the Ministry of Arid land, Kenya; and six farmers living in the region of Nairobi. Data collection and analysis are based on qualitative approach.

The written surveys were distributed hand to hand among NHMS' representatives who were present for a training session held in ICPAC, Nairobi, at the time of our field visit in February 2013. In addition, we sent the survey through email to the NHMSs who had not sent representatives to the training session. We received response from respondents in eight services. Questions in the surveys were divided into two main topics:

A first theme focused on the conception, implementation, and outcomes of the "Regional Climate Prediction and Risk Reduction in the Greater Horn of Africa" program. Questions included the respondent's knowledge/ awareness of the assessed program; effectiveness of this program, from his/her point of view; and progress made in climate monitoring activities after the program ended. The goal was to shed light on the program's effective contribution to improved HM risk management in the GHA.

A second set of questions focused on ICPAC and the regional forecasts regularly released in the GHA. Questions included: current climate modelling support provided by ICPAC, and the effectiveness of this support, according to the respondents; current level of coordination and communication among NHMSs; level of communication with potential forecast users in the ministries and in civil society; and suggestions to improve ICPAC's current activities to liaise better with forecast users, and to foster current DRR activities in each country. The purpose was to assess the quality and usefulness of the climate products produced with ICPAC support, and disseminated across the GHA two or three times a year.

Individual interviews with four project PIs in the program "Regional Climate Prediction and Risk Reduction in the Greater Horn of Africa" served to collect information on its conception and implementation and on the application of the demonstration activities. This was critical to assess challenges and successes in implementing pilot activities and to evaluate the long-term effectiveness of the DRR program. An individual interview with a meteorologist from KMD who regularly participate in the GHA Climate Outlook Forums (COFs) helped assessing the organization of these forums, including the type of invited participants and the major topics of the discussions.

Interviews with a member of the One Acre Fund, a representative of the Kenyan Ministry of Arid land, and farmers were aimed to extract qualitative information from actual and potential users of climate forecasts. For instance, we collected data on the current participation of representatives from the Ministry of Arid Land in COFs, as well as the actual use of climate forecasts by this Ministry. Subsequent interviews with a member of the local NGO One Acre Fund and with farmers helped complete the information regarding actual uses of climate forecasts to mitigate disasters' impacts on the ground, especially in the field of agriculture. Farmers were selected by a research associate, based in Nairobi, on a random basis. Unfortunately, due to a lack of time and opportunities to travel to more distant sites, other communities could not be studied.

The aim of the research was to evaluate disaster risk management in the GHA as of today, using literature and evaluating OFDA's program "Regional Climate Prediction and Risk Reduction in the Greater Horn of Africa", which served as a case study to complement data from the literature. A significant limit to the study was the difficulty encountered in gaining access to key information related to OFDA's program, which was completed in 2005. Some documents were missing; for example, no full evaluation of the program had been conducted when the project ended. 
Memory fades as time elapses, and some interviewees from the NHMSs had little memory of the program's specifics, while others had been recently hired by the meteorological service. Finally, on-site interviews were only conducted in Kenya due to time and resource constraints, which limits the scope of some results to this particular country. Comparing our findings with other evaluations of DRR in SSA was necessary to confirm the main outcomes.

\section{Results: Disaster Risk Reduction in the Greater Horn of Africa}

This section focuses on the conception and implementation of the program "Regional Climate Prediction and Risk Reduction in the Greater Horn of Africa" funded by OFDA between 2001 and 2005 in the GHA. More specifically, it assesses implemented activities and their impacts, with a long-term perspective. We focus on what was gained through this program, in terms of improved DRR practice in the GHA, what were the major problems during the implementation, and what are the remaining challengesin light of this program's successes and weaknesses.

\subsection{Impacts of the Disaster Risk Reduction Program}

At the end of 2001, OFDA's program "Regional Climate Prediction and Risk Reduction in the Greater Horn of Africa" was implemented across the GHA. Focusing on risk preparedness, this program's goal was to improve the prediction of hydrometeorological hazards, and mitigate their impacts on society. Spread over 3 years (until early 2005), the program received technical and technological support from several international research and climatebased centers. ICPAC was the key implementing agency. The main objective of this program was: "[...] to improve monitoring, prediction and applications for early warning of climatic hazard events in support of disaster reduction and other regional sustainable development objectives" (IRI 2001).

Reducing the impact of hydrometeorological hazards such as droughts and floods was at the core of this initiative. At the regional level, activities to enhance climate monitoring essentially focused on ICPAC, strengthening its key position as a regional climate platform in the GHA. In contrast, NHMS staff and collaborators were trained to strengthen national forecasting capacities within the GHA. Training sessions were organized by ICPAC staff and held in its office in Nairobi, which benefited from technological reinforcement throughout the "Regional Climate Prediction and Risk Reduction in the Greater Horn of Africa" program. For instance, ICPAC received computers to downscale national climate data, as well as technical support from IRI's collaborators. ICPAC was also in charge of the regular organization of the GHA COFs with support from OFDA and the IRI. Held twice a year, these forums prepared the groundwork for the release of regional seasonal climate outlooks before the main rainfall seasons (in August and February). Through this program, COFs were also used as vehicles to inform users outside of the climate field, for example, stakeholders in climate-sensitive sectors such as agriculture, water management, and health, about the potential implications of seasonal forecasts for their area of activity. Finally, at the local level, several demonstration activities were developed and applied to demonstrate the utility of integrating relevant climate information into the decision-making process.

A review of the program's documentation, combined with interviews and surveys sent to key informants, served to confirm a clear strengthening of ICPAC's position as a regional climate center in the GHA throughout the duration of the program "Regional Climate Prediction and Risk Reduction in the Greater Horn of Africa." This was achieved especially because of technology transfers and training sessions that enhanced ICPAC's staff forecasting capacities and skills. For instance, ICPAC received a "super computer" to analyze climate data and produce seasonal climate outlooks and selected members of the staff were trained abroad at international climate centers. During the program, ICPAC also received support organizing capacity-building sessions to train staff of the NHMSs; this platform possesses equipment to model regional and national seasonal forecasts.

With the goal to better link climate experts and stakeholders, capacity-building workshops were held as parallel events to the COFs during the program; representatives of climate sensitive sectors (users) were invited to attend. They were trained to better understand climate predictions-including the probability levels-and the potential risks affecting their specific sectors. According to interviews with ICPAC's staff, a majority of the invited users belonged to ministries and international nongovernmental organizations (such as the Red Cross), while smaller organizations, for example, farmers' associations, were absent. The fact that these local entities were not invited suggests a stronger focus of COFs' organizers on larger international institutions, which also provide fund and technical support to ICPAC. Yet, COFs' training sessions were designed to enhance users' capacities to develop and apply relevant policies and strategies to reduce disaster risks in their country. It should be noted that no follow up mechanisms were established to evaluate how the training session influenced concrete action and policy on the ground.

The main outcome of COFs was a regional seasonal climate outlook that was released twice a year, in time before the main rainfall seasons in most parts of the GHA. 
Preparation of the climate outlook was monitored at ICPAC during the program, with support from international climate institutes. The regional outlook was built using climate data collected by the NHMSs. The NHMSs were then responsible for disseminating the forecasts at the national level, using communication media such as radio, $\mathrm{TV}$, and newspaper. The climate outlooks were regional in nature and contained an advisory to users not to use the information as such, at national level, but to contact their respective NHMS for specific guidance.

Pilot projects were implemented at a local scale in different climate-sensitive sectors by ICPAC in partnership with representatives from those sectors. Among the pilot activities were: (1) the development of a user-friendly reservoir management decision support tool; (2) the use of climate information for farm level decision making; (3) the development of a climate-based food security early warning system; and (4) a Rift Valley fever outbreak early warning model. According to ICPAC's staff and other interviewees familiar with OFDA's pilot projects, at the end of the program only one of the pilot projects was close to completion. The three other projects needed further data, research, and investments to provide concrete outcomes or to validate climate-impacts models.

\subsection{Modeling Climate Forecasts Today}

When OFDA program's funding ended early 2005, implementation of the pilot projects stopped. However, other sources for technical and financial support contributed to enhance DRR activities in the GHA. Interviews with several members of ICPAC indicated that some funding and technical support was obtained from intergovernmental institutions and climate institutes, which helped ICPAC maintain and improve its forecasting activities up until the present. Thus ICPAC remains the main climate research center in the GHA, as well as a major regional platform where climate experts meet, are trained, and have access to the newest forecasting technologies and equipment to model their national seasonal forecasts.

The overall improved quality (since 2000) of the regional forecasts is recognized by all NHMSs interviewed for this study, including by representatives who were not personally involved in the program "Regional Climate Prediction and Risk Reduction in the Greater Horn of Africa" (Table 1). Table 1 also shows the high level of participation in the COFs among NHMSs. Recently (in 2011), a third annual meeting was established to better reflect the climate diversity among ICPAC's member states. Interviews with the representatives of the NHMSs also indicated that the third COF was required by "summer rainfall" countries. The tropical and eastern countries of the GHA have rainfall seasons between September and October, and between February to April, while others receive their rainfall between June and September (summer rainfalls). Until 2011, COFs were held at the end of August and beginning of February which was less relevant for countries depending on summer rainfall. A third annual $\mathrm{COF}$ is now routinely organized to release seasonal predictions in June. This session, however, does not yet provide the relevant workshops and training on forecast interpretations for users.

\subsection{Participation of Users in Forecasts' Production}

As recognized by most NHMSs, the gap between climate scientists and users of the forecasts is significant. The disconnection can be observed during the COFs, where most attendees belong to climate institutions (ICPAC, NHMSs, or international climate centers, for example, the World Meteorological Organization (WMO) - see the COF statement on http://icpac.net). Many interviews with potential local COF participants confirm a lack of participation in the COFs by local actors such as small NGOs and farmer' groups. This is essentially due to a lack of awareness about COFs' timing and venue (local actors are not informed about, nor invited to, these forums), which continues to hamper local users' participation to COFs, even today. In addition, local actors often have limited resources to participate (especially if a COF is held abroad). Most COFs are perceived as events for climate experts only, due to the high attendance from representatives of this category, which can discourage participation for groups working in other fields. The suggestion of a continuous ignorance from ICPAC of actors at the local level was confirmed by several interviewees.

In Kenya contacts between meteorologists and some policymakers seem to be regular, based on a discussion with a representative of the Ministry of Arid Land. According to the interviewee, the KMD regularly disseminates climate information within concerned ministries and their ministerial representatives frequently attend COFs. But ministerial representatives are not involved in the production of the seasonal outlooks, which is a process led only by climate experts. The interview also indicates that after each climate forecast COF ministries from climate-sensitive sectors in Kenya meet separately from ICPAC at the national level in order to discuss their understanding of the implications of the seasonal predictions on each climate-sensitive sector. It is unclear whether these discussions effectively lead to the adoption of relevant policy for DRR. Apparently a lack of financial resources hinders the development and implementation of many relevant measures to mitigate disaster risks. 
Table 1 Results from the surveys distributed to National Hydrometeorological Services in the Greater Horn of Africa

\begin{tabular}{lllll}
\hline NHMSs (surveys' respondents) & $\begin{array}{l}\text { Participation in } \\
\text { OFDA's Program }\end{array}$ & $\begin{array}{l}\text { Observed forecasts } \\
\text { improvements (Since 2000s) }\end{array}$ & $\begin{array}{l}\text { Received support } \\
\text { from ICPAC }\end{array}$ & $\begin{array}{l}\text { COF's regular } \\
\text { participation }\end{array}$ \\
\hline Ethiopia & Yes & Yes & Yes & Yes \\
Uganda & No & Yes & Yes & Yes \\
Burundi & Yes & Yes & Yes & Yes \\
Sudan & No & Yes & Yes & Yes \\
South Sudan & No & N/A & Yes & Yes \\
Tanzania & No & Yes & Yes & Yes \\
Kenya & No & Yes & Yes & Yes \\
Rwanda & Yes & Yes & & \\
\hline
\end{tabular}

Results were collected through surveys submitted to representatives of the NHMSs. Note that South Soudan officially exists since 2011. The recent creation of a meteorological center does not allow clear observation of forecast improvement. Eight NHMS representatives responded on: their involvement in the reviewed DRR program; perceived improvements in seasonal climate predictions since the program was implemented; support provided by ICPAC to model national forecasts; and their participation to the COFs

\subsection{Use of Forecast in Decision Making}

The tangible use of seasonal forecasts to mitigate or prevent critical hazard impacts at the national level also remains unclear. Based on interviews with the NHMSs, which agreed on the significant improvements of forecast quality since 2000 (Table 1), barriers to a "real-life" use of the forecasts include problems in forecast accuracy (for example, there is a need to update the equipment and the modeling techniques used by forecasters) and gaps in the communication loop with potential users. Lack of feedback from the users' community to the forecasters was indicated by some as impairing a complete evaluation of whether forecasts are used (if at all) in the GHA (Table 2). On the technical side, there is an ongoing need to improve forecast downscaling techniques in order to build products that are more accurate and reliable at the national and local levels, which was also raised by several interviewees.
Attempts to enhance use of the forecasts for decision making in the GHA were launched through several pilot projects implemented as part of the program "Regional Climate Prediction and Risk Reduction in the Greater Horn of Africa." But most pilot activities were not completed when the program ended (IRI 2005). Interviews with several key actors involved in these pilot projects highlighted multiple issues affecting the execution of these local initiatives, during and after the program's completion. This information is compiled in Table 3. For instance, many partners involved in demonstration activities such as "Food Security Outlooks (FSO) for contingency planning in the Greater Horn of Africa" and "Protecting pastoralist livelihoods by protecting livestock trade between the GHA and the Middle East through the control of Rift Valley Fever (RVF)" were outside of the "climate sphere" (for example, experts in agriculture or members of health departments) and were consulted about, rather than involved

Table 2 Use of climate forecast surveys by NHMSs in the GHA

\begin{tabular}{|c|c|}
\hline NHMSs & Perceived forecasts' utility in decision making at national level and needs to improve their usefulness \\
\hline Ethiopia & $\begin{array}{l}\text { Not sure about utility-problems of quality: need for new modeling techniques and better } \\
\text { infrastructures to produce seasonal predictions }\end{array}$ \\
\hline Uganda & Sure about utility—but problems of quality: need to improve climate analysis techniques \\
\hline Burundi & $\begin{array}{l}\text { Not sure about utility-problems of quality and communication with users: need to improve } \\
\text { climate modeling techniques }+ \text { need feedback from the user's community }\end{array}$ \\
\hline Sudan & $\begin{array}{l}\text { Sure about utility for some users-problems of communication and quality: forecast are difficult } \\
\text { to understand }+ \text { need to use more advanced climate model (for example, dynamic models) }\end{array}$ \\
\hline South Sudan & Sure about utility_-problems of communication: users often do not understand forecasts \\
\hline Tanzania & Not sure about utility - problems of communication: users often do not understand forecasts \\
\hline Kenya & Not sure about utility_problems of quality: need to improve climate modeling techniques \\
\hline Rwanda & Sure about utility_-but problems of communication: forecasts must be provided daily to users \\
\hline
\end{tabular}

Results were collected through surveys submitted to representatives of the NHMSs. Eight NHMSs representatives responded to questions on: forecast concrete utility in the GHA and problems to address in order to improve forecast use as decision-making tools 
Table 3 Interview results from key actors in the assessed DRR program pilot demonstration activities

\begin{tabular}{|c|c|c|c|}
\hline $\begin{array}{l}\text { Pilot projects implemented between } 2002 \text { and } \\
2005\end{array}$ & Achievements & Current status & $\begin{array}{l}\text { Reason for current } \\
\text { status }\end{array}$ \\
\hline $\begin{array}{l}\text { Hydropower stabilization and flood risk } \\
\text { management in the Tana River Basin, } \\
\text { Kenya }\end{array}$ & $\begin{array}{l}\text { Software to improve hydropower } \\
\text { production developed } \\
\text { Training of ICPAC experts } \\
\text { Consultation with representatives of } \\
\text { the energy sector (KenGen) }\end{array}$ & $\begin{array}{l}\text { Project never completed } \\
\text { (software never used) }\end{array}$ & $\begin{array}{l}\text { Lack of involvement of } \\
\text { relevant institutions } \\
\text { Lack of funds to } \\
\text { continue/conduct } \\
\text { remaining necessary } \\
\text { analysis }\end{array}$ \\
\hline $\begin{array}{l}\text { Flood livelihood impact assessment for } \\
\text { contingency planning in the Lower Tana } \\
\text { River Basin, Kenya }\end{array}$ & $\begin{array}{l}\text { Streamflow model and flood risk } \\
\text { maps developed } \\
\text { Livelihood baselines and } \\
\text { contigency plans prepared } \\
\text { Findings published }\end{array}$ & $\begin{array}{l}\text { Models and plans never } \\
\text { applied }\end{array}$ & $\begin{array}{l}\text { Lack of funds to } \\
\text { implement results }\end{array}$ \\
\hline $\begin{array}{l}\text { Improving agricultural production through } \\
\text { farm-level decision making: the case of the } \\
\text { Eastern Province, Kenya }\end{array}$ & $\begin{array}{l}\text { Results on how tailored information } \\
\text { for farmers can be used to identify } \\
\text { resource management decisions } \\
\text { Findings published by Ngugi et al. } \\
\text { (2011) }\end{array}$ & $\begin{array}{l}\text { Project completed in District } \\
\text { of Machakos in Kenya with } \\
\text { other support when the } \\
\text { program ended }\end{array}$ & $\begin{array}{l}\text { Project's PI able to } \\
\text { secure funds to } \\
\text { complete activities in } \\
\text { Kenya }\end{array}$ \\
\hline $\begin{array}{l}\text { Food Security Outlooks (FSO) for } \\
\text { contingency planning in the Greater Horn } \\
\text { of Africa }\end{array}$ & $\begin{array}{l}\text { FSO invited to COF } \\
\text { Climate experts acknowledging } \\
\text { opportunity to use their products } \\
\text { for concrete decision on the } \\
\text { agricultural sector }\end{array}$ & $\begin{array}{l}\text { Weak relationship between } \\
\text { climate experts and food } \\
\text { specialists }\end{array}$ & $\begin{array}{l}\text { Lack of funding } \\
\text { Very low involvement } \\
\text { of the user community } \\
\text { (the food security } \\
\text { community) } \\
\text { Lack of follow-up by } \\
\text { ICPAC }\end{array}$ \\
\hline $\begin{array}{l}\text { Protecting pastoralist livelihoods by } \\
\text { protecting livestock trade between the } \\
\text { GHA and the Middle East through the } \\
\text { control of Rift Valley Fever (RVF) }\end{array}$ & $\begin{array}{l}\text { A prototype environmentally-based } \\
\text { RVF risk model neared } \\
\text { completion }\end{array}$ & Project never completed & $\begin{array}{l}\text { Departure of the project } \\
\text { coordinator when the } \\
\text { funding ended } \\
\text { Reluctance to cooperate } \\
\text { from countries not } \\
\text { involved at the onset }\end{array}$ \\
\hline
\end{tabular}

Questions were asked about the achievements, current status, and reasons for failure/success of each pilot activity

in, the conception and implementation of the pilot projects. Yet, these partners were actual users of the forecasts thus the projects would have benefited from their inclusion at the onset. This limited role for potential contributors and users spread a general feeling of exclusion of nonclimate experts from meaningful participation in decision making in the pilot projects. In fact, the meteorologists were the real drivers of all demonstration initiatives.

The case of the Tana River hydropower project is also an interesting example illustrating how a lack of coordination and initial involvement of all relevant institutions from the beginning of a project can compromise the implementation of promising activities. This project was significant for Kenya because it related to the generation of hydropower energy, which is important for the country's economy and electricity supply. The project was, however, never completed and contradictory explanations were provided by interviewees, suggesting conflicts of interest between meteorologists and experts in the energy sector, lack of involvement of the nonclimate expert partners, and reservations about sharing critical data among climate and energy experts.

The exception is the Machacos pilot project on farm level decision making that was completed after the end of the OFDA project because the coordinator (PI) was completely involved and dedicated to the activities, and was able to secure funding from other donors, such as the European Union (EU).

\subsection{Communication Among Climate Experts, Stakeholders, and Local Users}

Communication gaps seem to significantly hinder DRR activities in the GHA. Interviews with NHMS staff and with farmers indicate that communication infrastructure to disseminate relevant climate information at the local level is missing. There also is no training among climate-sensitive communities (for example, farmers), on how to use forecasts as decision-making support tools (Fig. 3). Figure 3 also shows that communication gaps include the use 
Fig. 3 Improving decision making based on the climate forecasts of NHMSs in the GHA. Note Results were collected through surveys submitted to representatives of the NHMSs. Questions asked were focused on what is needed to improve forecasts' utility in decision making in the GHA; surveyed respondents provided more than one response

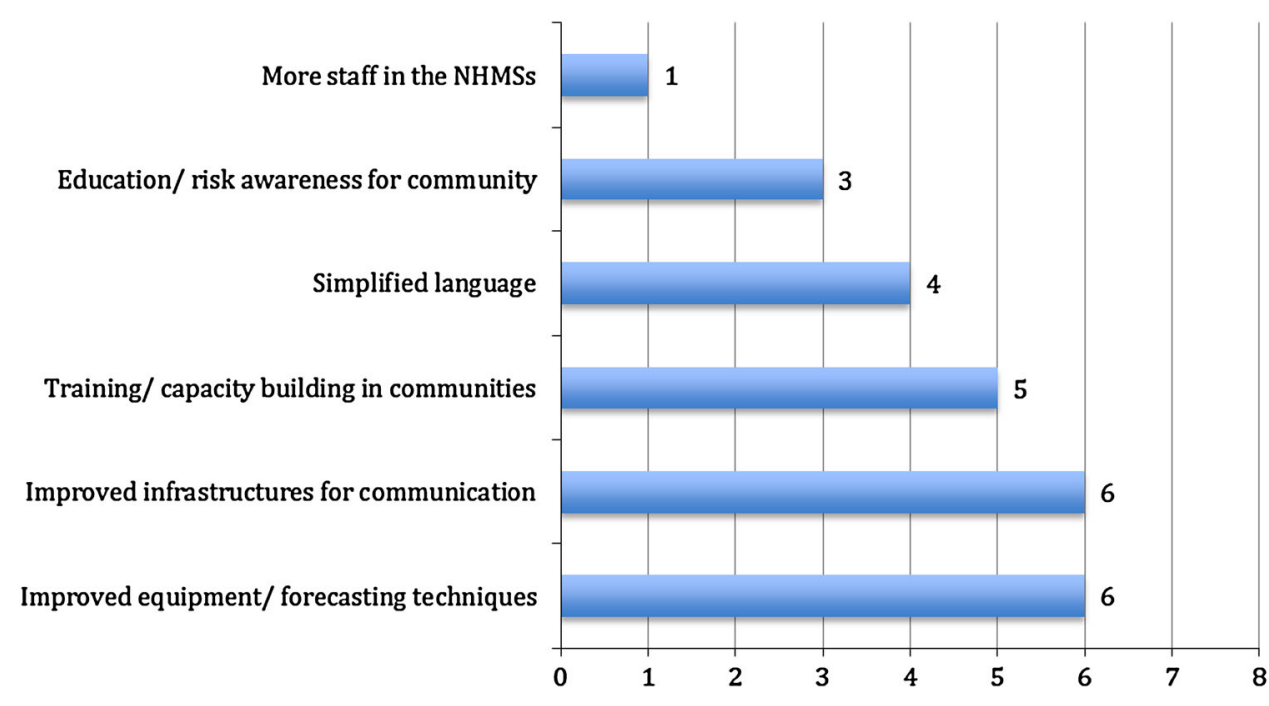

of complex terminology when seasonal climate outlooks are disseminated after the COFs. For instance, the use of probabilistic terms (for example, the probability of rain at a "normal", "below normal", or "above normal" level) often is outside local experience and language. This is a language barrier that clearly limits the understanding and interpretation of forecasts, even by some highly educated users. Nonetheless, information collected from the NHMSs reveals a certain degree of awareness of communication biases with respect to the local communities, and a degree of willingness to address these issues.

Discussions with farmers in rural communities around Nairobi confirmed and illustrated that the information provided by the NHMSs' representatives failed to connect with local experience and perceived needs. Most farmers are not familiar with meteorological terms; and many do not have access to climate or weather information, because they are located in remote areas and/or do not possess communication devices (for example, TV or radio). Moreover, trust issues towards forecasts were revealed, because of past inaccuracies in climate predictions (which essentially relates to misinterpretation of the probabilistic language of forecasts), lack of interactions between farmers and scientists, and existing local system of knowledge on climate and seasonal patterns, whose relevance for decision making (for instance, in agriculture) has been demonstrated by Campbell (1999), Speranza et al. (2009), Archer (2003), and Hansen et al. (2011), among others.

\section{Discussions and Conclusions}

This section discusses the main outcome of our study, with the objective to highlight strengths and weaknesses, as well as challenges in implementing DRR activities in the GHA.
We conclude by identifying lessons that are yet to be learned and applied, in order to improve risk preparedness and responses at the local level in the region-and more widely, in countries affected by climate-related hazards.

\subsection{Strengths, Weaknesses, and Opportunities for Disaster Risk Reduction in the Greater Horn of Africa}

Results from this study highlight some of the main strengths and weaknesses in the practice of DRR in the GHA. These strengths and weaknesses can be related, to some extent, to the way DRR is conceived and implemented by international aid agencies, climate experts, and national governments.

A long-term impact of OFDA's program "Regional Climate Prediction and Risk Reduction in the Greater Horn of Africa" is reflected in the position ICPAC holds today. It has remained the main climate center of the GHA, and its role is critical in supporting training activities for hydrometeorologists of member countries, promoting regional cooperation, and offering technical support to downscale regional and national seasonal predictions. In addition, the quality of climate predictions has significantly improved over the past 15 years throughout the region (Hellmuth et al. 2007). These DRR programs can be useful to initiate significant progress in the field of HM risk forecasting. But further improvements, especially in the accuracy of local climate prediction, are still required (Ngugi et al. 2011).

A concern that remains is how to reflect the diversity of climate and seasonal patterns across the GHA. Although ICPAC has recently launched a third annual COFs to release seasonal outlooks that match the needs of the "summer rainfall countries," related training sessions for 
decision makers have yet to be organized. These sessions are substantive and intended to enable users to use forecasts in decision making.

On this matter, the role of ICPAC as the primary climate platform in the GHA is open to question, due to a high seasonal diversity across the region. A critical need is to produce more locally-accurate forecasts, and to provide adequate support for forecast's users in each specific climate zone. To fine tune climate forecasts linked to the needs of local decisions makers, the establishment of the decentralized antenna of local climate monitoring centers is important. Creating climate platforms for each specific agroecological zone would facilitate the collecting and monitoring of local data. This decentralization would contribute to production of more reliable and accurate forecasts for each specific zone. Moreover, holding COFs in each decentralized climate center, with a focus on one specific agroecological system in the GHA, could be a pathway to better address users' needs in terms of climate products that are relevant as decision-support tools.

Even precise and accurate forecasts by themselves are not sufficient to reduce hazardous impacts on society (Buchanan-Smith et al. 1994; Bailey 2013). This research demonstrates a lack of concrete use of the climate information, when released in its aggregated form after each COF. To initiate concrete action and policy, forecasts could be converted into comprehensive advisories based on the real needs of decision makers at all levels. Producing such "usable science" (Glantz 2004) also implies creation of feedback loops from the forecast users to the climate experts. Feedback loops would ensure that users' needs are integrated into the conception of climate outlooks (Basher 2006; Kelman and Glantz 2014). It would mean that forecasts' production is not driven by climate experts (as it is today), but is conceived as a social activity that takes root in local society (Holloway 2003; Basher 2006; Holloway and Roomaney 2008; Glantz and Baudoin 2014; Kelman and Glantz 2014).

Communication gaps between climate scientists and the society are important barrier to release "user-friendly" climate products. Bridges needs to be built between the forecasters and the population, and also between the forecasters and the policymakers. This is critical to enhance risk preparedness among African governments. For instance, many Sub-Saharan African governments are currently unprepared to respond in time to climate alerts (UNISDR 2012). But building bridges among all relevant partners to strengthen DRR is not an easy task, as demonstrated by the pilot initiatives initiated in the DRR program. The study reveals the significant challenges of working successfully on issues that are multisectoral and multinational. This highlights the need to involve, equally, all partners-especially those outside of the "climate science sphere"-at the onset of a project to avoid tensions. Capacity building for relevant partners is also necessary and opportunities for training are present, for instance through COFs. These forums could serve as a vehicle to better connect all proponents (climate experts, decision makers, and local representatives of the communities) and effectively apply a feedback loop among them.

Finally, DRR activities also need to take place at the local level, where hazards hit. For instance, training local advisers and representatives of local communities is critical in order to increase their understanding of seasonal forecasts, and to foster their capacities to raise awareness among their communities. The benefits of using relevant climate information at the local level, for example for agriculture, have been highlighted in many studies (Archer 2003; Hansen et al. 2011; Ngugi et al. 2011). A two-way dialogue between climate experts and local communities (or their representatives) should be launched to build trust and respect. Trust could be gained, for instance, if existing local knowledge and observations of climate and seasonal patterns are perceived and used as valuable information for the production of forecasts. After all, local villagers are long-term witnesses of their environment and its changes (Campbell 1999; Speranza et al. 2009; Baudoin et al. 2014). Other opportunities include improving communication means, for example, using cellphone to better disseminate climate information and warnings in remote areas where such devices are frequently used (Glantz and Baudoin 2014).

\subsection{Final Words: Lessons from the Greater Horn of Africa}

Building linkages among climate scientists, decision makers, and local communities is a key towards building a more risk-resilient society. The following set of lessons, extracted from this research, is proposed to contribute to DRR in the GHA as well as other hazard-sensitive regions. Most of these lessons are not new as they were highlighted in other studies (Glantz 2000; Hellmuth et al. 2007; Glantz and Baudoin 2014). Thus, what we often call a "lesson learned" is truly not yet a lesson applied in practice.

- Being a catalyst, providing initial support to enhance the position of relevant national/regional institutions in a beneficiary country, is a key role for aid agencies: a catalyst initiates transformation that ensures long-term outcomes, even after funding for a project ends;

- Progress in forecasting technologies remains necessary, but must target users' needs: these needs must first be assessed in order to be addressed;

- Language is a fundamental: user-friendly climate products must be built with inputs from their end 
users, using understandable terminology, and be disseminated using appropriate media for large coverage;

- Capacity building is critical in DRR activities: it must concern climate scientists, decision-making institutions, and beneficiary communities;

- DRR is not a climate-centered activity: it is before all a societal process, which needs to be considered as such if climate products are to be useful to mitigate HM risks; and

- Bridges must be built, among climate scientists, policymakers, and local communities to ensure collaboration and feedback loops among these key actors.

Moreover, our conclusions suggest the need to build bridges among the following field of activity: DRR, climate change adaptation, and development. DRR is not a separate field of activity from development issues, and both are concerned with climate change and the risks of increased HM hazards. Hence, those involved in these fields of activity must develop partnerships instead of working as separate units, sometimes within the same institution, with a high risk of spending resources on similar activities or even of leading to maladaptation and competition.

Acknowledgments This study is part of the research program: "Hydro-Meteorological Disaster Risk Reduction and Climate Change: Lessons Learned for Resilient Adaptation to a Changing Climate". It was made possible through the support of the Office of US Foreign Disaster Assistance, Bureau for Democracy, Conflict and Humanitarian Assistance, US Agency for International Development. The opinions expressed in this article are those of the authors and do not necessarily reflect views of the US Agency for International Development. The authors also wish to acknowledge with much appreciation members of the following organizations who provided their time, energy, and ideas: the IGAD Climate Prediction and Applications Centre (ICPAC in Nairobi), NOAA's National Weather Service, the University of Nairobi, the University of Colorado, the Kenya Meteorological Department (KMD) and One Acre Fund NGO. In addition, we give a special thanks to Peter and Ann Usher for their support and warm welcome during the field investigations conducted in Nairobi.

Open Access This article is distributed under the terms of the Creative Commons Attribution License which permits any use, distribution, and reproduction in any medium, provided the original author(s) and the source are credited.

\section{References}

Archer, E.R.M. 2003. Identifying underserved end-user groups in the provision of climate information. Bulletin of the American Meteorological Society 11(84): 1525-1532.

Bailey, R. 2013. Managing famine risk: Linking early warning to early action. London: Chatham House.

Basher, R. 2006. Global early warning systems for natural hazards: Systematic and people-centered. Philosophical Transactions of the Royal Society A 364: 2167-2182.

Baudoin, M.-A. 2012. Climate change adaptation in rural Africa: The case of farmers' communities in Southern Benin (Etude de l'adaptation aux changements climatiques des populations rurales africaines: le cas de communautés rurales agricoles au sud du Bénin). Brussels: Université Libre de Bruxelles.

Baudoin, M.-A., A. Cuni-Sanchez, and B. Fandohan. 2014. Small scale farmers' vulnerability to climatic changes in southern Benin: The importance of farmers' perceptions of existing institutions. Mitigation and Adaptation Strategies for Global Change 19(8): 1195-1207.

Buchanan-Smith, M., S. Davies, and C. Petty. 1994. Food security: Let them eat information. IDS Bulleting 25(2): 69-80.

Campbell, D.J. 1999. Response to drought among farmers and herders in southern Kajiado District, Kenya: A comparison of 1972-1976 and 1994-1995. Human Ecology 27(3): 377-416.

Clark, H. 2012. Building resilience: The importance of prioritizing disaster risk reduction. Canterbury: UN Hopkins Lecture, University of Canterbury, 15 August 2012.

Ferris, E., and D. Petz. 2012. The year that shook the rich: A review of natural disasters in 2011. Washington: Brookings Institution, London School of Economics.

Glantz, M.H., M. Betsill, and K. Crandall. 1997. Food security in Southern Africa: Assessing the use and value of ENSO information. Boulder: National Corporation for Atmospheric Research.

Glantz, M.H. 2000. Reducing the impact of environmental emergencies through early warning and preparedness: The case of the 1997-1998 El Niño. Lessons learned from the 1997-1998 El Niño: Once burned, twice shy? Tokyo: United Nations Environment Programme, National Center for Atmospheric Research, United Nations University, World Meteorological Organization, United Nations International Strategy for Disaster Reduction

Glantz, M.H. 2004. Usable science 8: Early warning systems: Do's and dont's. Darby: Diane Pub.

Glantz, M.H., and M.-A. Baudoin. 2014. Working with a changing climate, not against it-Hydro-meteorological disaster risk reduction: A survey of lessons learned for resilient adaptation to a changing climate. Boulder: Consortium for Capacity Building.

Hansen, J.W., S.J. Mason, L. Sun, and A. Tall. 2011. Review of seasonal climate forecasting for agriculture in sub-Saharan Africa. Experimental Agriculture 47(S2): 205-240.

Hellmuth, M.E., A. Moorhead, M.C. Thompson, and J. Williams (eds.). 2007. Climate risk management in Africa: Learning from practice. New York: Columbia University's International Research Institute for Climate and Society (IRI).

Holloway, A. 2003. Disaster risk reduction in Southern Africa. African Security Review 12(1): 29-38.

Holloway, A., and R. Roomaney. 2008. Weathering the storm: Participatory risk assessment for international settlements. Cape Town: Disaster Mitigation for Sustainable Livelihoods Programme (PeriPeri), University of Cape Town.

Holloway, A., F. Fortune, and V. Chasi. 2010. RADAR Western Cape 2010: Risk and development annual review. Cape Town: Disaster Mitigation for Sustainable Livelihoods Programme (PeriPeri), University of Cape Town.

IFPRI (International Food Policy Research Institute). n.d. http://www. ifpri.org. Accessed 10 Feb 2015.

IPCC (Intergovernmental Panel on Climate Change). 2007. Climate change 2007: The IPCC fourth assessment report. Cambridge: Cambridge University Press.

IPCC (Intergovernmental Panel on Climate Change). 2012. Special report on managing the risks of extreme events and disasters to advance climate change adaptation. Cambridge, UK: Cambridge University Press.

IRI (International Research Institute for Climate and Society). 2001. Regional climate prediction and risk reduction in the Greater Horn of Africa. The IRI proposal to USAID/OFDA. 
IRI (International Research Institute for Climate and Society). 2005. Regional climate prediction and risk reduction in the Great Horn of Africa. The IRI final report to USAID/OFDA.

Kelman, I., and M.H. Glantz. 2014. Early warning systems defined. In Preventing disaster: Early warning systems for climate change, ed. A. Singh, and Z. Zommers, 89-108. London: Springer.

Lallau, B. 2008. African farmers between vulnerability and resilience. Promoting a capacity building approach for risk management (Les agriculteurs africains entre vulnérabilité et résilience. Pour une approche par les capacités de la gestion des risques). Revue Française de socio économie 1: 177-198.

Ngugi, R.K., S.M. Mureihi, and P.N. Kamande. 2011. Climate forecast information: The status, need and expectations among smallholder agro-pastoralists in Machakos District, Kenya. International Journal of Current Research 11(3): 6-12.

Nicholson, S.E. 2014. A detailed look at the recent drought situation in the Greater Horn of Africa. Journal of Arid Environments 104: 71-79.

Ogallo, L., P. Bessemoulin, J.P. Ceron, S. Mason, and S. Connor. 2008. Adapting to climate variability and change: The climate outlook forum process. WMO Bulletin 57(2): 93-102.

Reliefweb. n.d. http://www.reliefweb.int. Accessed 17 Feb 2015.

Shah, P., C.I. Speranza, R. Opiyo, and J. Ngaina. 2012. Options for improving the communication of seasonal rainfall forecasts to smallholder farmers: The case of Kenya. Bonn: German Development Institute/Deutsches Institut für Entwicklungspolitik (DIE).

Speranza, C.I., B. Kiteme, P. Ambenje, U. Wiesmann, and S. Makali. 2009. Indigenous knowledge related to climate variability and change: Insights from droughts in semi-arid areas of former Makueni District, Kenya. Climate Change 100(2): 295-315.
Stern, N. 2007. Stern review on the economics of climate change. Cambridge: Cabinet Office \& HM Treasury, Cambridge University Press.

UNECA (United Nations Economic Commission for Africa). 2011. Vulnerability and climate change hotspots in Africa-Mapping based on existing knowledge. Working paper 2. Addis Ababa: African Climate Policy Centre (ACPC).

UNISDR (United Nations International Strategy for Disaster Reduction). 2012. Disaster reduction in Africa: UNISDR informsSpecial issue on drought risk reduction 2012. Geneva: UNISDR Informs.

USAID (United States Agency for International Development). 2012. Building resilience to recurrent crisis: USAID policy and program guidance. Washington: USAID Publication.

Vermaak, J., and D. van Niekerk. 2004. Disaster risk reduction initiatives in South Africa. Development Southern Africa 21(3): 555-574.

Wolde-Georgis, T. 1997. El Nino and drought early warning in Ethiopia. Internet Journal of African Studies No. 2. http://www. papers.ssrn.com/sol3/papers.cfm?abstract_id=1589710. Accessed 17 Feb 2015.

World Bank. 2010. Report on the status of disaster risk reduction in Sub-Saharan African. Washington: The World Bank and Global Facility for Disaster Reduction and Recovery (GFDRR).

World Bank. 2012. Disaster risk financing and insurance in SubSaharan Africa: Review and options for consideration. http:// www.preventionweb.net/go/31323. Accessed 11 Feb 2014.

World Bank. 2013. Turn down the heat: Climate extremes, regional impacts and the case for resilience. A report for the World Bank by the Potsdam Institute for Climate Impact Research and Climate Analytics. Washington. 